\title{
Evaluation of the User Experience of a Standard Telecare Product - the Personal Trigger
}

\author{
Andrea Taylor, Stefan Agamanolis \\ Distance Lab \\ Forres, Scotland \\ \{andrea, stefan\}@distancelab.org
}

\begin{abstract}
Telecare is a term that covers a range of products and services that use new technology to enable people to live with greater independence and safety in their own homes. In this paper, we present an evaluation of the user experience of a familiar telecare product called a 'personal trigger' that provides a means of summoning assistance when help is needed. It is supplied as part of a community alarm service and should be worn at all times for continuous protection. Our evaluation is based on a survey distributed to over 1,300 clients in Moray, North East Scotland with a $60 \%$ response rate. The main findings are: clients view the service extremely positively, but almost two-thirds have never used their personal trigger to summon help and less than $8 \%$ wear it at all times; over twothirds of clients wear their personal trigger most or all of the time, predominantly because it makes them feel safer; almost one-third of clients wear their personal trigger only some of the time to not at all, mostly because it is too sensitive or they forget to put it on. The appearance of the personal trigger was found to be less significant, despite the large majority of respondents being women. However, there is a need for better design to make it more comfortable and enjoyable to wear. Over the coming years, many older people will have higher expectations of public services. Designers can make things that are attractive and work well, and should be included in teams that develop telecare technology.
\end{abstract}

Keywords-client survey; community alarm button; community alarm service; design; older people; pendant button; personal trigger; telecare

\section{INTRODUCTION}

The delivery of healthcare is changing in response to an ageing population, the growth in long-term conditions, and the rising trend in emergency admissions to hospital among older people. Healthcare has been hospital centred and reactive. The evolving model of care emphasises care in the community and preventive care, and high tech solutions such as telecare. Telecare is a term that covers a range of products and services that use new technology to monitor risks and environmental conditions around the home, raising an alert if help is needed. Products include flood and gas detectors, a falls detector, epilepsy and enuresis sensors, and a property exit sensor. In Scotland, Government is committed to supporting development and installation of telecare technology, to help people to live with greater independence and safety in their own homes and avoid going into residential care, which is usually more expensive for care providers. The telecare market is small, but growing. Products and services can be bought directly from specialist shops and suppliers or may be offered by the local authority social work services as part of a package of care.

Teams of clinicians and engineers develop much of this new technology, where the emphasis is on solving problems and producing a functional object, and consideration for the user experience - what it feels like to own or to use a product or service - is limited. Consequently, products tend to have a medical or security aesthetic that can be considered ugly and intrusive when placed in the home or worn on the body. In 'Design Meets Disability', Pullin argues that designers working from an art school culture, such as jewellery designers and fashion designers, should be included in teams that develop medical products to balance technical development with design sensibilities and open up new approaches to problem-solving [1]. Pullin cites reading glasses as exemplifying design for disability: there is no stigma attached (wearing glasses is not commonly seen as having a disability); and they are fashionable and enjoyable to wear. However, he points out that this has not always been the case. In the 1930s, the National Health Service (NHS) maintained that its glasses should not be 'styled' but only 'adequate' even though they were known to make people feel ashamed. In the 1970s, the importance of styling was acknowledged, but not applied in order to limit demand. In the meantime, less utilitarian-looking glasses could be bought privately. Today, fashionable glasses are widely available; glasses have become acceptable and desirable, no longer a humiliation. Telecare is more likely to emulate this success if designers are included in teams that develop products and services, and there is a move away from a purely technical approach.

This paper presents an evaluation of the user experience of a standard telecare product called a 'personal trigger' (also known as a community alarm button or pendant button) that is supplied as part of a community alarm service. Our evaluation is based on a survey of over 1,300 clients in a remote and rural region in North East Scotland called Moray, in collaboration with Moray Community Health and Social Care Partnership (MCHSCP). MCHSCP brings together acute, primary, public health, social work and mental health services for a population of 90,000. NHS Grampian and the Moray Council are the "parent" organisations for MCHSCP. The structure of this paper is as follows. Section II describes the community alarm service and personal trigger. Sections 
III and IV present and discuss the survey results. Section V describes related work. Section VI concludes our paper.

\section{COMMUnity AlARM SERVICE AND PERSONAL TRIGGER}

The community alarm service is a widely implemented telecare service that supports people living in their own homes by providing a means of summoning assistance when help is needed. The service has evolved from the alarm systems of the 1960s, which were designed for tenants living in sheltered housing without access to a telephone, and consisted of a pull-cord linked to an audio box on the wall to speak to a warden. Today's community alarm service consists of a base unit, a personal (radio) trigger worn with a neck cord, wrist strap, or clothing clip, and call handling (Fig. 1).

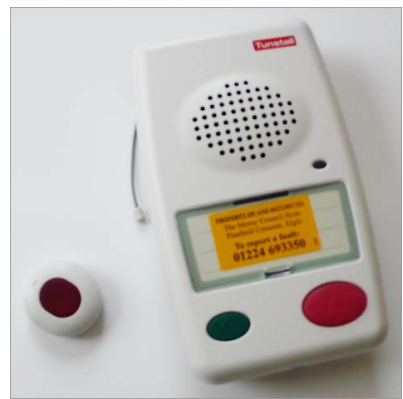

Figure 1. A community alarm service base unit and personal trigger

The base unit incorporates a large emergency alarm button and is plugged into the mains electricity supply and a home telephone line. Pressing the button on the base unit alerts the Call Monitoring Centre that help is needed. Centre staff are able to talk with the caller through a speakerphone on the unit to decide on a course of action. Or, if the caller is unable to speak for any reason, the Emergency Services or a designated carer will be alerted to attend. Pressing the button on the personal trigger also raises a call through the base unit, provided it is within range (up to 50 meters).

The personal trigger is the prevailing solution to the need for some form of user-activation in a crisis - the least dependable aspect is the need for people to wear or carry it at all times. Regrettably, personal triggers tend to have a security aesthetic that is impersonal and conspicuous when worn (Fig. 2).

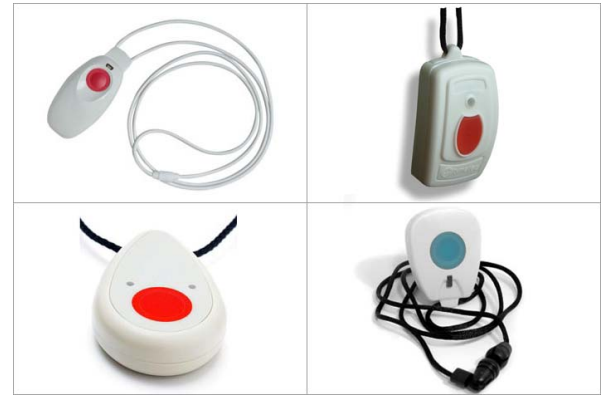

Figure 2. The personal trigger has a common appearance across suppliers that is impersonal and conspicuous

\section{USER EXPERIENCE EVALUATION}

Distance Lab, in collaboration with MCHSCP, issued a survey on the personal trigger to 1324 community alarm service clients. Tunstall is the main supplier in Moray [2]. Not all clients have the exact same model - some have older and some have newer versions - however, the essential look and feel, the way that it works and the way that it is worn is consistent (Fig. 3).

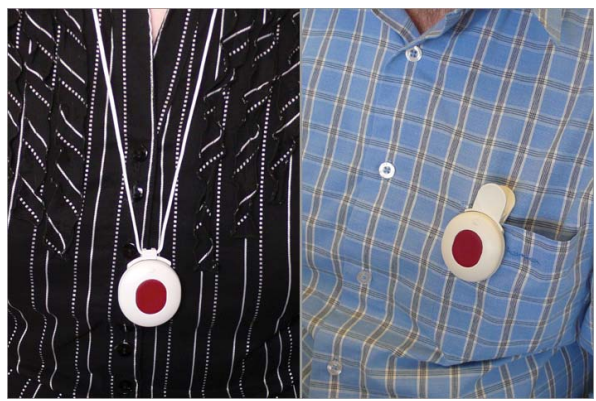

Figure 3. The personal trigger can be worn around the neck or wrist, or clipped to clothing

The motivation for this study was two-fold: verbal accounts from practitioners that many people do not wear their personal trigger; likewise, a telephone survey of 200 community alarm service clients in Scotland in 2003, which found only $21 \%$ wearing their trigger at the time of the call [3]. Distance Lab wanted an up-to-date gauge of the problem to assess if there is a need or desire for design improvements or change. MCHSCP wanted to assess, on a person-byperson basis, whether the service is still beneficial and follow up as needed. For this reason, the survey was nonanonymous.

The format of the survey was multiple-choice questions and space for free text comments. We had a very good response rate of $60 \%$ ( 795 returns). A further 26 returned the form uncompleted and indicated that the service was no longer relevant to them.

\section{A. Background Information}

Clients were asked their age and sex, whether they live alone, and why they were given a personal trigger. Respondents are mostly women (79\%), and aged 75 years and over $(79 \%)$. A small percentage is under 50 years $(2.6 \%)$. Most live on their own $(81 \%)$, and most were given a personal trigger because they live alone $(73 \%)$ and/or because of mobility issues (74\%). People were also given the equipment because they have a long-term illness $(38 \%)$ or their family suggested it (28\%).

\section{B. Use of the Service (Questions 1-3)}

Clients were asked how long they have had a personal trigger (table 1). They were asked how many times they have used it to summon help (table 2), and how many times they have wanted to use it but it was out of reach (table 3). Almost two-thirds of people have had their trigger for up to four years, and most have not yet needed or wanted to use it. However, a significant minority (11\%) has found themselves 
without their trigger when it was needed - less so after the first occasion, suggesting people learn the hard way to wear or keep it close-by. One respondent wrote 'I forget. I do not realise how essential it is but I am now beginning to realise that I have no other means of help if I am on my own'.

TABLE I. Number of YeArs Using THE SERVICE

\begin{tabular}{|l|l|c|}
\hline & $\begin{array}{c}\text { Response } \\
\text { Percent }\end{array}$ & $\begin{array}{c}\text { Response } \\
\text { Count }\end{array}$ \\
\hline Less than one year & $15.7 \%$ & 125 \\
\hline 1-2 years & $24.7 \%$ & 196 \\
\hline 3-4 years & $22.4 \%$ & 178 \\
\hline More than 4 years & $36.0 \%$ & 286 \\
\hline Total & & 785 \\
\hline
\end{tabular}

TABLE II. Number OF TIMES Trigger USEd TO SUMMON HelP

\begin{tabular}{|l|l|l|}
\hline & \multicolumn{1}{|c|}{$\begin{array}{c}\text { Response } \\
\text { Percent }\end{array}$} & $\begin{array}{c}\text { Response } \\
\text { Count }\end{array}$ \\
\hline $\mathbf{0}$ & $\mathbf{6 4 . 9 \%}$ & $\mathbf{5 1 6}$ \\
\hline 1 & $10.4 \%$ & 83 \\
\hline 2 & $7.4 \%$ & 59 \\
\hline More than 2 & $15.3 \%$ & 122 \\
\hline Total & & 780 \\
\hline
\end{tabular}

TABLE III. NUMBER OF TIMES TRIgGER OUT OF REACH

\begin{tabular}{|l|l|l|}
\hline & $\begin{array}{c}\text { Response } \\
\text { Percent }\end{array}$ & $\begin{array}{c}\text { Response } \\
\text { Count }\end{array}$ \\
\hline $\mathbf{0}$ & $\mathbf{8 4 . 8 \%}$ & $\mathbf{6 7 4}$ \\
\hline 1 & $7.0 \%$ & 56 \\
\hline 2 & $2.1 \%$ & 17 \\
\hline More than 2 & $2.1 \%$ & 17 \\
\hline Total & & 764 \\
\hline
\end{tabular}

\section{Wearing and Not Wearing the Trigger (Questions 5-6)}

Clients were asked how often they wear their personal trigger (table 4). Those who answered other than 'Not at all' were then asked when they removed it (table 5). Nearly onethird of clients wear their trigger only some of the time, very occasionally, or not at all, diluting the effectiveness of the service. Contrary to expectation, the majority of clients said that they wear their trigger all or most of the time. However, most remove it at night and when leaving the house. It is also removed in the shower or bath, when a carer or loved-one is in the house, at the kitchen sink, and in the garden. One respondent wrote (she removes it) 'If I am wearing unsuitable clothing, it is too obvious'. Just a small percentage does not remove their personal trigger at any time $(8 \%)$. Not surprisingly, more than one in ten people have wanted to use their personal trigger but found it out of reach. Clients are advised to remove their trigger for sleeping to avoid strangulation. The problem is that people forget to put it on again when getting out of bed during the night, when accidents frequently occur. One respondent wrote 'The advice is not to wear it in bed; as I have to get up a lot at night, I forget to put it on in every trip to the bathroom which is when I'm vulnerable'. According to Tunstall, 70\% of falls occur at night and falls account for $10 \%$ of acute hospital admissions in the UK each year [4]. For older people, the consequences of a fall can be fatal.
TABLE IV. HOW OFTEN TRIGGER IS WORN

\begin{tabular}{|l|l|l|}
\hline & $\begin{array}{c}\text { Response } \\
\text { Percent }\end{array}$ & $\begin{array}{c}\text { Response } \\
\text { Count }\end{array}$ \\
\hline All or most of the time & $\mathbf{6 9 . 1 \%}$ & $\mathbf{5 4 9}$ \\
\hline Some of the time & $6.0 \%$ & 48 \\
\hline Very occasionally & $18.1 \%$ & 144 \\
\hline Not at all & $6.0 \%$ & 48 \\
\hline Total & & 789 \\
\hline
\end{tabular}

TABLE V. WHEN TRIGGER IS NOT WORN

\begin{tabular}{|l|l|l|}
\hline & $\begin{array}{c}\text { Response } \\
\text { Percent }\end{array}$ & $\begin{array}{c}\text { Response } \\
\text { Count }\end{array}$ \\
\hline At night & $\mathbf{6 7 . 4 \%}$ & $\mathbf{5 3 6}$ \\
\hline In the shower or bath & $44.0 \%$ & 350 \\
\hline Leaving the house & $\mathbf{6 8 . 4 \%}$ & $\mathbf{5 4 4}$ \\
\hline No, I keep it on at all times & $7.5 \%$ & 60 \\
\hline Other & $5.9 \%$ & 47 \\
\hline
\end{tabular}

\section{Reasons for Wearing and Not Wearing the Trigger (Question 7)}

Clients were asked the main reason for wearing or not wearing their personal trigger. Most people wear their trigger because it makes them feel safe and it gives their family peace of mind (table 6). This is as intended - the service is designed to provide confidence to the client and their relatives that, if needed, help can be summoned. Other reasons include feeling supported, feeling more independent, feeling less anxious and stressed, and needing less help from family members. The main reasons people do not wear their trigger are because they could press it by accident and they forget to put it on (table 7). The sensitivity of the button emerged as a strong theme, with clients reporting that it is very easily set off e.g. when holding a small grandchild or by doing light housework. One respondent wrote 'Sometimes this makes me take it off'. Other reasons for non-wear include not wanting to be a nuisance, not wanting to be labeled as vulnerable, and the trigger is uncomfortable or annoying to wear. Many people commented that the cord is irritating to the skin. A few people commented that they only wear their trigger when they feel they need to, and prefer it to be hidden. Contrary to expectation, especially as the large majority of respondents were women, a lesser reason for not wearing the trigger is that it is unattractive.

TABLE VI. REASONS FOR WEARING TRIGGER

\begin{tabular}{|l|l|l|}
\hline I feel safer & $\begin{array}{c}\text { Response } \\
\text { Percent }\end{array}$ & $\begin{array}{c}\text { Response } \\
\text { Count }\end{array}$ \\
\hline I feel more independent & $\mathbf{6 8 . 4 \%}$ & $\mathbf{5 5 4}$ \\
\hline It gives my family peace of mind & $31.2 \%$ & 248 \\
\hline I feel supported & $55.7 \%$ & 443 \\
\hline I feel less anxious and stressed & $35.8 \%$ & 285 \\
\hline I need less help from my family & $29.7 \%$ & 236 \\
\hline Other & $10.8 \%$ & 86 \\
\hline
\end{tabular}


TABLE VII. REASONS FOR NOT WEARING TRIGGER

\begin{tabular}{|l|l|l|}
\hline & $\begin{array}{c}\text { Response } \\
\text { Percent }\end{array}$ & $\begin{array}{c}\text { Response } \\
\text { Count }\end{array}$ \\
\hline I don't want to be a nuisance & $6.5 \%$ & 52 \\
\hline It's uncomfortable / annoying to wear & $4.8 \%$ & 38 \\
\hline It labels me as vulnerable & $2.1 \%$ & 17 \\
\hline I forget to put it on & $\mathbf{1 2 . 8 \%}$ & $\mathbf{1 0 2}$ \\
\hline It's unattractive & $3.0 \%$ & 24 \\
\hline I could press it by accident & $\mathbf{1 8 . 5 \%}$ & $\mathbf{1 4 7}$ \\
\hline Other & $6.8 \%$ & 54 \\
\hline
\end{tabular}

\section{E. Suggested Changes to the Trigger (Question 8)}

Clients were given a list of changes to the personal trigger that other people have suggested, and asked to tick those they agree with (table 8). Most wanted the trigger to send a call for help if they have a heavy fall, and for the trigger to work outside their home. Some, including people who are blind, wanted a trigger that did not need to be worn, e.g. a voice activated trigger. A small minority wanted added functionality, such as incorporating a watch or music player into the trigger. Again, contrary to expectation, making the trigger more attractive and available in a range of styles and colours was a less popular suggestion.

TABLE VIII. SUgGESTED ChANGES TO THE TRIGGER

\begin{tabular}{|l|l|l|}
\hline & $\begin{array}{c}\text { Response } \\
\text { Percent }\end{array}$ & $\begin{array}{c}\text { Reponse } \\
\text { Count }\end{array}$ \\
\hline It would work outside my home & $\mathbf{5 4 . 1 \%}$ & $\mathbf{4 2 9}$ \\
\hline $\begin{array}{l}\text { It would have added functionality (e.g. } \\
\text { work as a watch or music player) }\end{array}$ & $8.8 \%$ & 70 \\
\hline $\begin{array}{l}\text { It would send a call for help if I have a } \\
\text { heavy fall }\end{array}$ & $\mathbf{6 9 . 1 \%}$ & $\mathbf{5 4 9}$ \\
\hline $\begin{array}{l}\text { It would be more attractive (e.g. made as } \\
\text { jewellery) and come in a range of styles } \\
\text { and colours }\end{array}$ & $12.7 \%$ & 101 \\
\hline $\begin{array}{l}\text { It would not need to be worn (e.g. a voice } \\
\text { activated trigger) }\end{array}$ & $21.5 \%$ & 171 \\
\hline
\end{tabular}

\section{F. Other Ideas for Changes to the Trigger (Question 9)}

Clients were asked what they would change about their personal trigger and why. In order of number of comments received, the ideas concentrated on: keeping things as they are; aesthetics; button sensitivity; and conspicuity.

Nothing! Some wanted no change emphatically and others because nothing seemingly came to mind. E.g. a respondent both told us that he doesn't wear his trigger because it is uncomfortable/annoying but he would change nothing.

- 'Billy would not change anything. He said it has a function and works well. It is not a toy and should not be dressed to look like a toy'

- 'Nothing. It serves the purpose as it is. No need to change style or colour. If anyone wants more jewellery they should buy their own'

- 'I personally do not think it requires any changes. It is after all a protection device not an entertainment centre!! It works well and as they say 'if it ain't broke - why fix it?"

- 'No change - I am 90 and don't know about these things'
- 'Nothing, except to make it more user friendly'.

Aesthetics Comments on the way that the personal trigger looks were mostly focused on the cord: the cord irritates the skin (some had an allergic reaction), the cord is unsightly, and the cord gets dirty. Two ladies had taken the initiative and replaced the cord with a ribbon to stop skin irritation and a silver chain that doesn't show under lower neck jerseys. Others also suggested a chain rather than a cord, as well a choice of colours to suit clothing. The cord is available in white only and looks grubby over time; indeed, MCHSCP can identify those who do not wear their personal trigger by the whiteness of the cord. Further, the cord does not have an adjustable fastener to allow people to wear their trigger at any length. This can be a problem, especially for women; the too-long cord dangles and knocks against objects, accidentally sending an alert call.

- 'I think a small chain would be better. Nothing that costs much and ask people to buy them"

- 'The string gets dirty and unattractive'

- 'I'm under $5 \mathrm{ft}$ and found it pressing against cooker, sink etc. accidentally'.

Sensitivity Many people commented that the trigger is too easily activated going about daily business. A wrist-worn version was suggested as less likely to be pressed accidentally.

- 'If possible I tuck the alarm in my bra to prevent activating it accidentally. Would be better if the alarm could be worn more safely with the minimum risk of accidentally activating it'

- 'I have thought about this quite a lot. It does get in the way. When bending, it swings about - why not make it like a watch or pin on a brooch smaller in shape. Then I would be able to wear it without worrying that it will go off when I don't need it or when I do some housework'.

Conspicuity Several people told us that they would like their personal trigger to be less bulky and less conspicuous, and to look more like a piece of jewellery.

- 'I find it is very obvious worn around my neck and generally wear a necklace to try to cover it'

- 'I am not vain, but if people see it, they comment on it, and why am I wearing one when I am not a pensioner. It can be a life safer, but I hate the comments'

- 'I don't like to wear it outside my clothes when I am in company - I realise this is foolish pride'

- 'It's cumbersome, awkward under summer clothing'

- 'I would prefer a gadget that could be worn as a brooch as I have to wear my glasses round my neck on a cord and I tend to get the cords mixed up together'

- 'Be more attractive. The string shows with a lot of my tops and I don't like that'.

G. No Longer Relevant (Question 10)

Clients were asked to tick a box if they felt the equipment they had was no longer relevant or beneficial - 32 people $(0.02 \%)$ so indicated. 


\section{H. Further Comments (Question 11)}

Space at the end of the survey was provided for free text comments about the service. Mostly, people used this space to give positive feedback about the service and express their gratitude, e.g., 'I stated that I live alone, but thanks to my alarm system I have plenty of help locally I can call on'. Some commented that a two-way speaker on the button would enable people to talk to someone if they needed help away from the home unit, e.g. in the garden, and others reiterated a desire for a device less easily triggered.

\section{DISCUSSION}

Our findings are similar to a study in 1993 that examined the use and acceptability of a community alarm service among 124 residents in sheltered accommodation [5]. Over one-third had never used the alarm and none of the 19 residents supplied with a personal trigger to wear did so, because it was considered too sensitive or unattractive. Nonetheless, most felt that the service was useful and provided reassurance. Our evaluation found that almost twothirds of clients have not used their trigger to summon help, yet over a third have had the trigger for more than four years and over two-thirds wear it all or most of the time - just $7.5 \%$ wear it at all times. Allocation of the service will be reviewed by MCHSCP, based on the survey results. Also, we suspect that the number who says that they wear their trigger all or most of the time is exaggerated. E.g. one respondent both told us that he wears his trigger all or most of the time and that he tries to remember it every now and then! Our evaluation also found that people do not wear their trigger for fear of giving false alarms and because of their own forgetfulness. The sensitivity of the device may need to be reworked. Contrary to [5], aesthetics was found to be less significant, despite the large majority of respondents being women. Just a small percentage do not wear their trigger because it is unattractive and making it more attractive and available in a range of styles and colours was one of the least popular changes we suggested. Distance Lab plan to probe the disparity. However, there could be several reasons why those surveyed do not consider the attractiveness of the trigger to be of utmost importance:

- By the time people are old enough to need a personal trigger, functionality is simply more important than looks and self-image/personal expression

- Respondents may not have wanted to appear unappreciative. The majority were aged 75 years and over with more than one-third over 85 years - the veteran generation tends to respect authority and be happier with what they are given. E.g. a respondent wrote 'Really quite happy with the one I have got. After all, it is for our own good. And we should be thankful to have such a button to hand'. However, the next generation of retirees - baby boomers - will place more demand on healthcare services

- Most clients were given a personal trigger because they live alone and/or because of mobility issues. Presumably, people become less concerned with how they look as they spend more time at home alone. Further, the trigger is removed when leaving the house because it will not work and when a carer or loved-one is in the house because it is not needed i.e. when others are around to see. People may feel differently if the trigger worked outside the home or if they lived in sheltered housing with shared facilities e.g., a communal lounge or gardens.

Notwithstanding, the survey findings show both a need and a desire to improve/innovate the cord (material, length, colour), the button (sensitivity, size), and the plastic clip. The clip is an impractical and rarely chosen option because people have difficulty opening it and it is easily knocked off.

The survey shows that people would like the trigger to work outside the home. One client wrote 'The one thing I find difficult is always to be close to a phone. I'm on my own all day but I have my friend at night so I don't venture out on my own as the button wouldn't really help me even if I fell in the garden.' Mobile phone technology offers one solution that can reduce the potential to constrain people to their own home in this way, e.g. Home Telehealth's 'Easy 5 Mobile Care Phone' [6] works anywhere there is mobile phone coverage. The survey also shows that people would like the trigger to send a call for help if they have a heavy fall. MCHSCP plan to make review visits to those clients to assess whether they would benefit from a falls detector. A falls detector is a small telecare sensor that is (also) linked to the Call Monitoring Centre through the base unit. Worn around the waist, the falls detector senses impact and then a change in orientation from vertical to horizontal. The falls detector also incorporates an alarm button, which when pressed, activates the community alarm service, so there is no need to wear the personal trigger at the same time. However, the falls detector is more expensive than a standard trigger and thus, in Moray, they are issued on a needs basis.

\section{RELATED WORK}

\section{A. Enhanced Telecare}

One response to the problem of people not wearing their personal trigger at all times has been to use additional sensors (linked to the Call Monitoring Centre through the telecare base unit) and monitoring technologies, which do not require a button to be pressed to summon help. E.g. a chair or bed occupancy sensor will raise an alert if the client has left their chair or bed and not returned within a preset time period, indicating a potential fall. The bed sensor can also be used to turn on lights, helping people to find their way to and from bed easily. A property exit sensor will raise an alert if the client leaves their house and doesn't return during certain times. Computer systems utilising door and movement detectors are also available to monitor the client's general level of activity within their home, such as how often they visit the kitchen and bathroom or whether they have got up in the morning. Care professionals can view the information through a website to help them recognise and manage any emerging problems. Presently, enhanced telecare supports rather than replaces the personal trigger because there remains the need for some self-initiated means to get help quickly when accidents occur. 


\section{B. Philips Lifeline}

Some personal triggers are larger and heavier than others, some have a built in speaker and microphone to enable twoway speech [7], some use mobile phone technology to work outside the home, and some are incorporated into a watch to reduce the stigma associated with having the community alarm service [8]. However, the look and feel is largely consistent: awkward and graceless. An exception is Philips Lifeline Classic Pendant (Fig. 4), which was designed with the look of jewellery to encourage people to wear it throughout the day [9]. The Classic Pendant is ivory coloured with gold-tone bead and button, and comes with a black, adjustable neck cord that is made of hypoallergenic material. The Classic Pendant acknowledges the importance of styling, self-image and how others see us. It illustrates a move towards a user-centred focus on quality of life; in this respect, it is interesting to draw a parallel with the history of reading glasses and those few manufacturers offering fashionable glasses that led to a change in the NHS model.

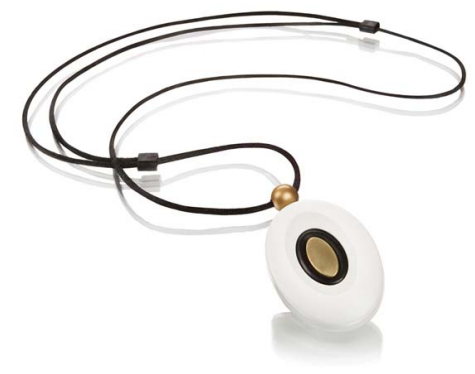

Figure 4. Philips Lifeline Classic Pendant, designed with the look of jewellery

\section{Hearwear}

'Hearwear: The Future of Hearing' was a project by RNID, the UK's largest charity for deaf and hard of hearing people, that asked whether hearing aids could become as fashionable and desirable as reading glasses [10]. RNID teamed up with Blueprint design magazine and 15 contemporary UK product designers to re-think hearing products from a fresh and less technological perspective. The resulting designs and prototypes were exhibited at the V\&A Museum in London, 2005-6. The display showed revolutionary and stylish new possibilities in hearing products, some like jewellery, and highlighted the massive potential for industry to create products that people not only need but will really want to wear.

\section{CONCLUSION}

The number of people requiring care is likely to grow; people are living longer but are increasingly living alone and without the support of an extended family. Telecare can make it easier for people to live independently at home, and the UK government has provided guidance and funding to mainstream availability by 2010 [11].

The community alarm service is already a mainstream care option - around 1.4 million people in the UK were linked to a service in 2005 [11]. This paper has presented research on the user experience of the personal trigger that is supplied as part of a community alarm service. Our evaluation is based on a survey of over 1,300 clients in Moray, North East Scotland. We found that: clients view the service extremely positively, but almost two-thirds have never used their personal trigger to summon help; over twothirds wear their personal trigger all or most of the time, predominantly because it makes them feel safer; almost onethird of clients wear their personal trigger only some of the time to not at all, mostly because it is perceived as too sensitive or they forget to put it on. Although the appearance of the personal trigger was found to be less significant, despite the large majority of respondents being women, there is a need for better design to make it more comfortable and enjoyable to wear. Over the coming years, many older people will have higher expectations of public services. Too often telecare equipment is conceived and designed with a purely technical and functional approach. It is important to also address aesthetics and what it feels like to own a product or use a service. Designers can make things that are attractive and work well, and should be included in teams that develop telecare technology.

\section{ACKNOWLEDGMENT}

We thank Lorna Bernard at MCHSCP and MCHSCP clients in Moray.

\section{REFERENCES}

[1] G. Pullin, "Design Meets Disability", Cambridge: The MIT Press, 2009.

[2] Tunstall, "Tunstall", Last accessed 9 September 2009, http://www.tunstall.co.uk/

[3] M.A. Blythe, A.F. Monk, and K. Doughty, "Socially dependable design: The challenge of ageing populations for HCI," Interacting With Computers, 17 (6), Dec. 2005, pp. 678-679, doi:10.1016/j.intcom.2005.09.005.

[4] Tunstall, "Falls", Last accessed 26 August 2009, http://www.tunstall.co.uk/main.aspx?PageID=43

[5] K. Davies, "The views of elderly people on emergency alarm use", Clinical Rehabilitation, Vol. 7, No. 4, 1993, pp. 278-282, doi: 10.1177/026921559300700402

[6] Home Telehealth, "Easy 5 Mobile Care Phone and Social Alarm", Last accessed 25 August 2009, http://www.hometelehealthltd.co.uk/easy5.htm

[7] TeleMedCare, "Telemedcare Voice Garde", Last accessed 26 August 2009, http://www.telemedcare.co.uk/socialalarm.html

[8] Tunstall, "Minute Watch", Last accessed 7 August 2009, http://www.tunstall.co.uk/assets/Literature/Minuet_data_sheet.pdf

[9] Philips, "Classic Pendant Personal Help Button", Last accessed 26 August 2009, http://www.lifelinesys.com/content/lifelineproducts/classic-pendant.jsp

[10] RNID, "Hearwear - the future of hearing", Last accessed 26 August 2009 , http://www.rnid.org.uk/information_resources/hearing_aids/hearwear

[11] Department of Health, "Building telecare in England", Last accessed 26 August 2009, http://www.dh.gov.uk/en/Publicationsandstatistics/Publications/Publi cationsPolicyAndGuidance/DH_4115303 